\title{
The Musical Hospital
}

\section{How Flattened and Fractured Brass, Wood and Stringed Instruments Are Repaired}

\author{
By Albert A. Hopkins
}

W HEN you go to the opera or a concert you see the 列 the orchestra. On the left at front are the first violins, behind them are the violoncellos and the double basses, In the center are flutes, piccolos, oboes, English horns, clarinets, horns, bassoons, trumpets and drums; on the conductor's right are the drums; on the conductor's right are the bones, while in the center at the back are bones, while in the center at the back are in brief, the orchestral scheme. Few people, however, when they view a perfectly balanced orchestra, realize that many of the instruments are subject to accidents which, for a time, incapacitate them from giving forth their accustomed sounds. It is our privilege to show some illustrations is our privi musical hospital," which has advantages over the ordinary hospital in that there are no ambulances and the patients never die. So the atmosphere is always cheerful and "atmosphere" is used advisedly for there is no other place on earth with so much local color as a musician's repair shop. Of course there are forign musicians with Of course there are fore the flowing ties and the uncut if not unkempt hair which go to make up the artistic personality. But for most of the ar-
tists their instruments are their breadtists their instruments are their breadwinners and few musicians achieve such a meed of success that they have many replicas of treasured instruments.

The things which can happen to a musical instrument are legion. There may be a train wreck, a trolley car may go wrong or an automobile run over the musical treasure, but all is grist to the repair shop. It should be stated, however, that instruments are grouped int classes and a man who repairs brass doe not try his hand at the wooden wind instruments, such as flutes, oboes, clarinets, saxophones and bassoons; while the stringed instruments have special and highly skilled surgeons all their own.

The brass instrument shop is the most picturesque of all, which may be gathered from our cover engraving which we are permitted to show through the courtesy of Mr. H. Gerson of Carl Fischer's in New York. Here instruments such as horns, trumpets, trombones, tubas, etc., undergo revivifying processes so that the former revivifying processes so that the former

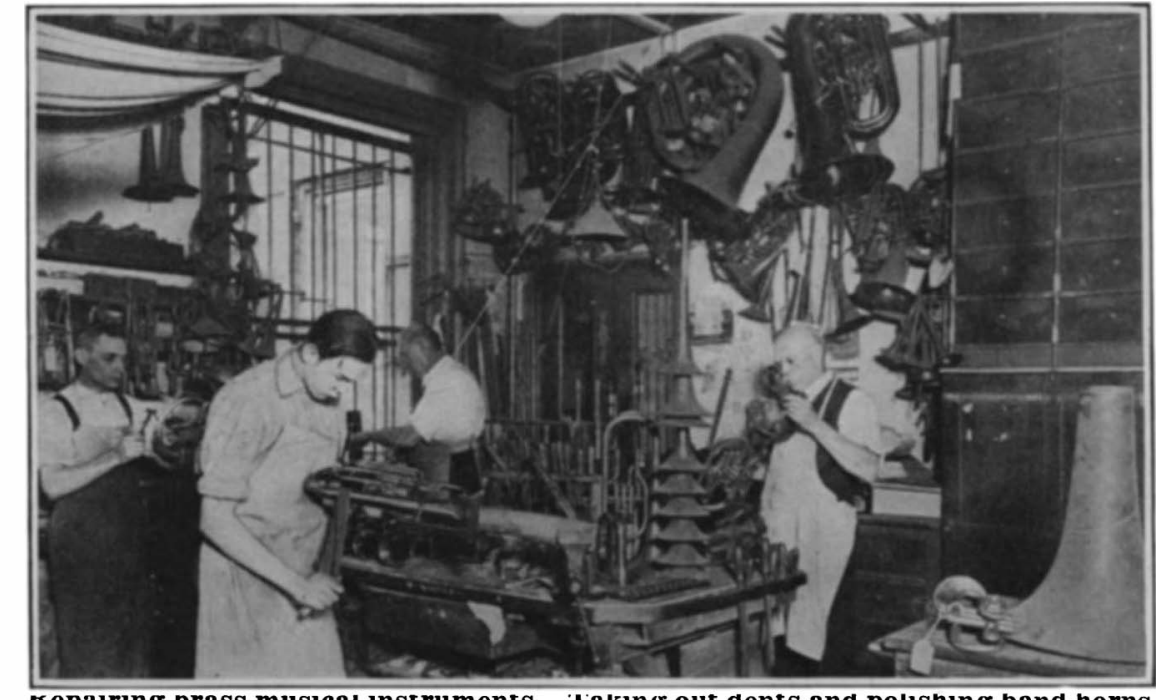

kepairing prass musical instruments. Taking out dents and polishing band horns

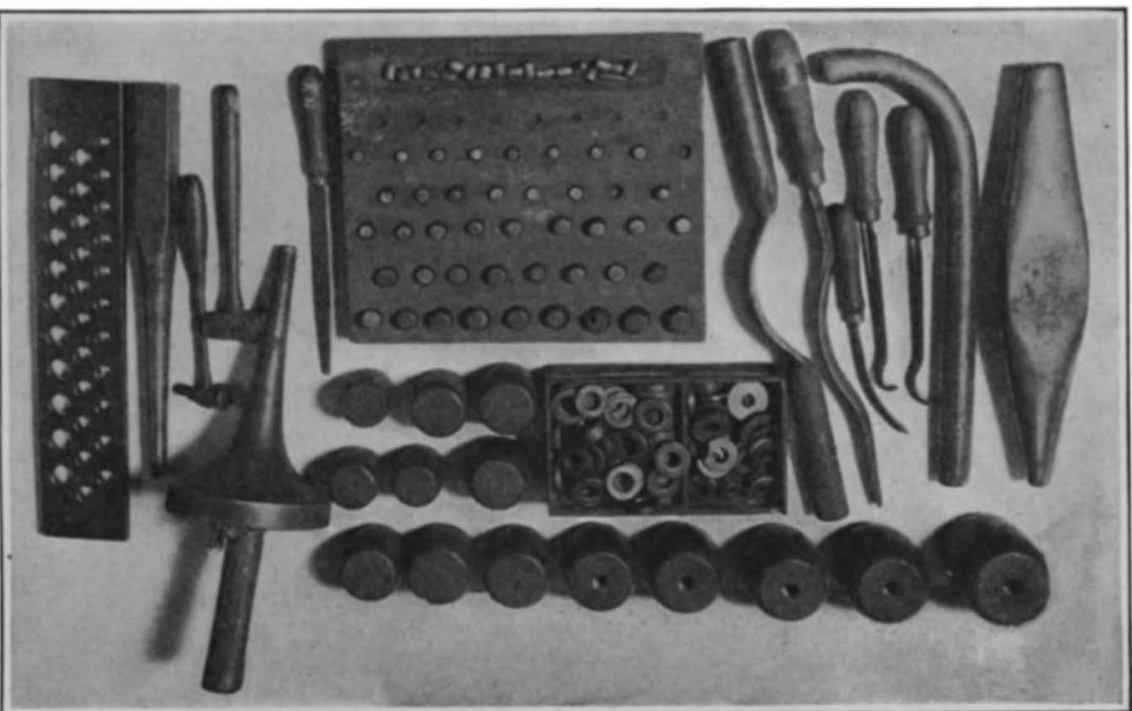

Tools for taking out dents in brass musical instruments. The balls are in successive sizes and are introduced into the bells and tubes carcass to the cellar of the junk man as old brass, but not so does the musical instrument repairer consider it. Men in this trade are of unusual intelligence arid withal have a mesting operation is the taking out of dents and the reforming of flattened horns without unbrazing the bells. This is accomplished by a series of cylinders or rather portions of cylinders, balls, washers and oddshaped pieces of metal of graduated size which are introduced into the bell, tube or slide. All sizes are provided so that no tube is too small; special hammers do the rest after the balls are wedged in and dents are thus perfectly obliterated. One of our engravings shows a rather full outfit of tools for this purpose. Of course valves become worn, leaky and otherwise out of order and here other specialists are called in; a man who works on piston valves rarely repairs circular valves and vice versa. The wood-wind shop adjoins and is not as picturesque as is the brass shop, neither is the string shop, but the results obtained in the latter are most extraordinary of all. A violin, a viola, a violoncello or a double-bass is sometimes put out of commission by an accident such as an automobile running over it. Almost any virtuoso will tell you that his instrument was improved in tone after a bad smash-up and subsequent repair. We do not believe that is true, as a rule, but there are cases which certainly go to prove it.

There are certain technical terms, as the back, belly and sides, to be considered, for the violin contains in its interior a mass of air which is let out by the $f-f$ holes. There is also the neck, scroll, the bridge, the pegs and the strings, and, last but not least, the varnish which plays such an important part in the tone. If a bridge, tailpiece, or the neck and scroll are destroyed it is an easy matter to replace them; but not so the back, belly and sides, which are made of seasoned wood sometimes hundreds of years old. The tools of the violin maker are peculiar and consist of those which would be found in any cabinetmaker's shop, plus iron clamps, scrapers, oval planes (often of minute size as planes go), calipers, purfling gages, chisels and many other special tools. (Continued on page 280 )

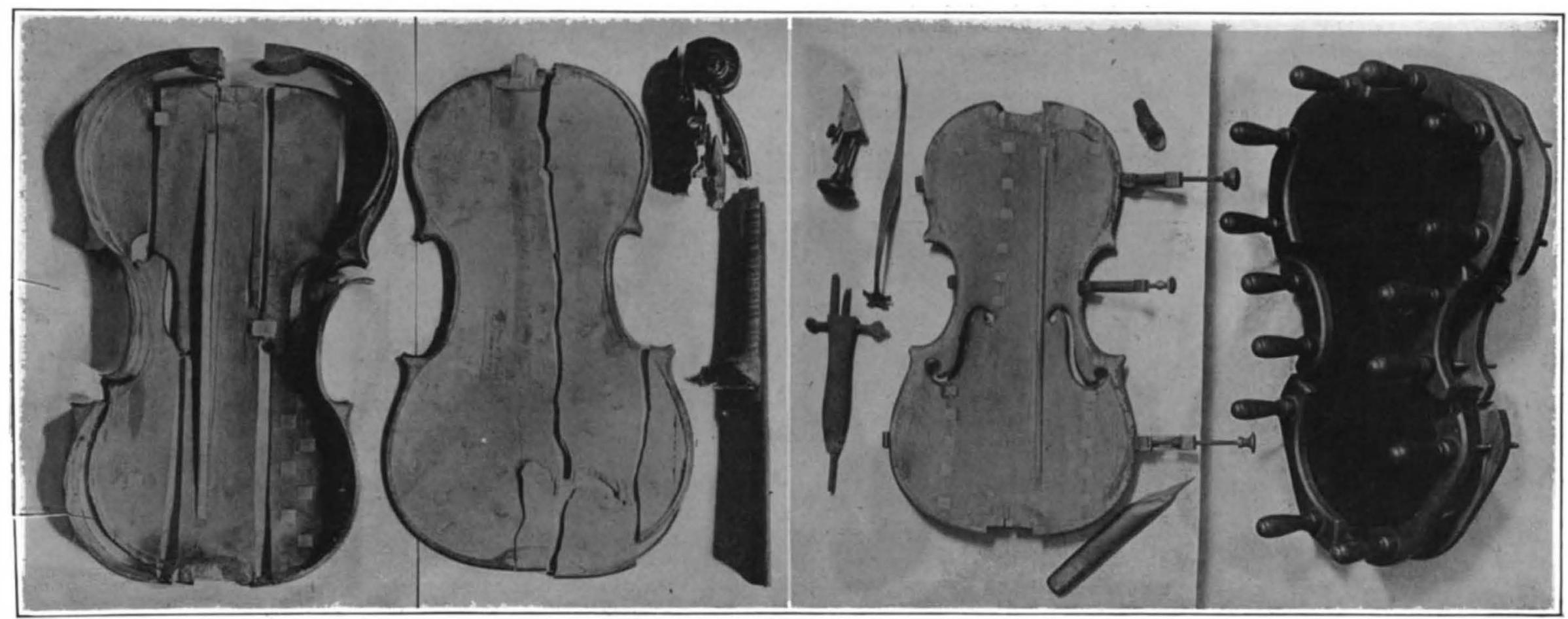

Left. Repairing the damage by gluing up the cracks. A valuable Genoese violin of 1779. Right: Clamping the belly of a violin to close up cracks and clamping the glued sides to the back and belly 


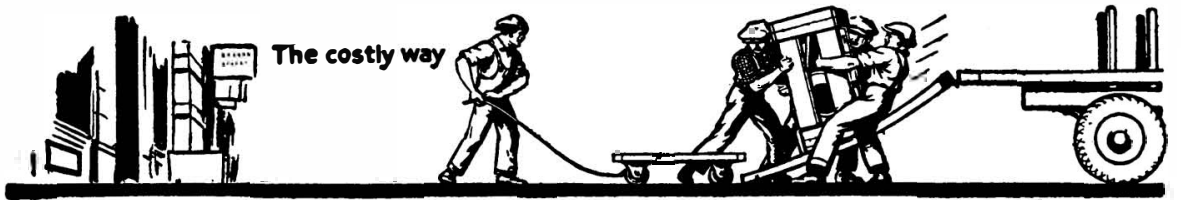

\section{Muscle costs more than machines}

DAYING machine-production wages today to men who use only their muscle, is the height of extravagance.

One man, with the aid of a

\section{Yale Spur-geared \\ Block and Trolley}

can lift and move your heavy loads safely and economically, and help cut your production costs to the bone. The Yale way will pay you a substantial and steady return in the saving of time and muscle.

Yale Spur-geared, Screw-geared and Differential Chain Blocks, Yale Electric Hoists and Yale Electric Industrial Trucks are fully described in booklets which will be sent on request.

The Yale \& Towne Mfg. Co. Stamford, Conn., U. S. A.

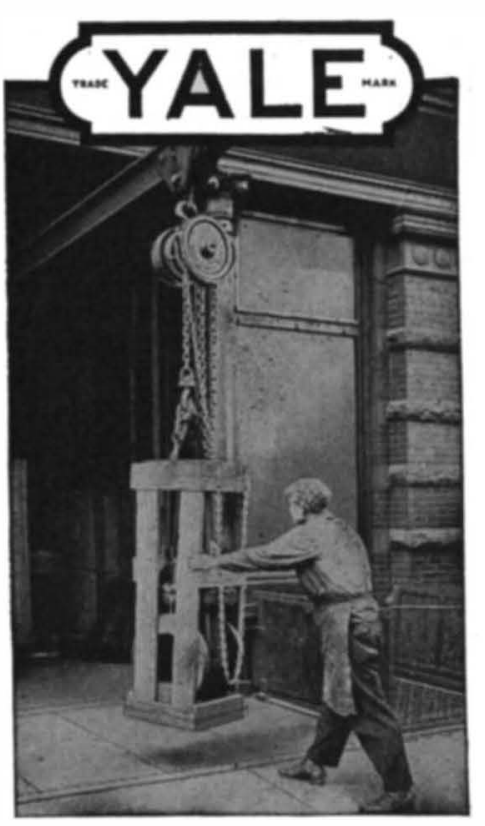

The Yale Way

Yale Made is Yale Marked
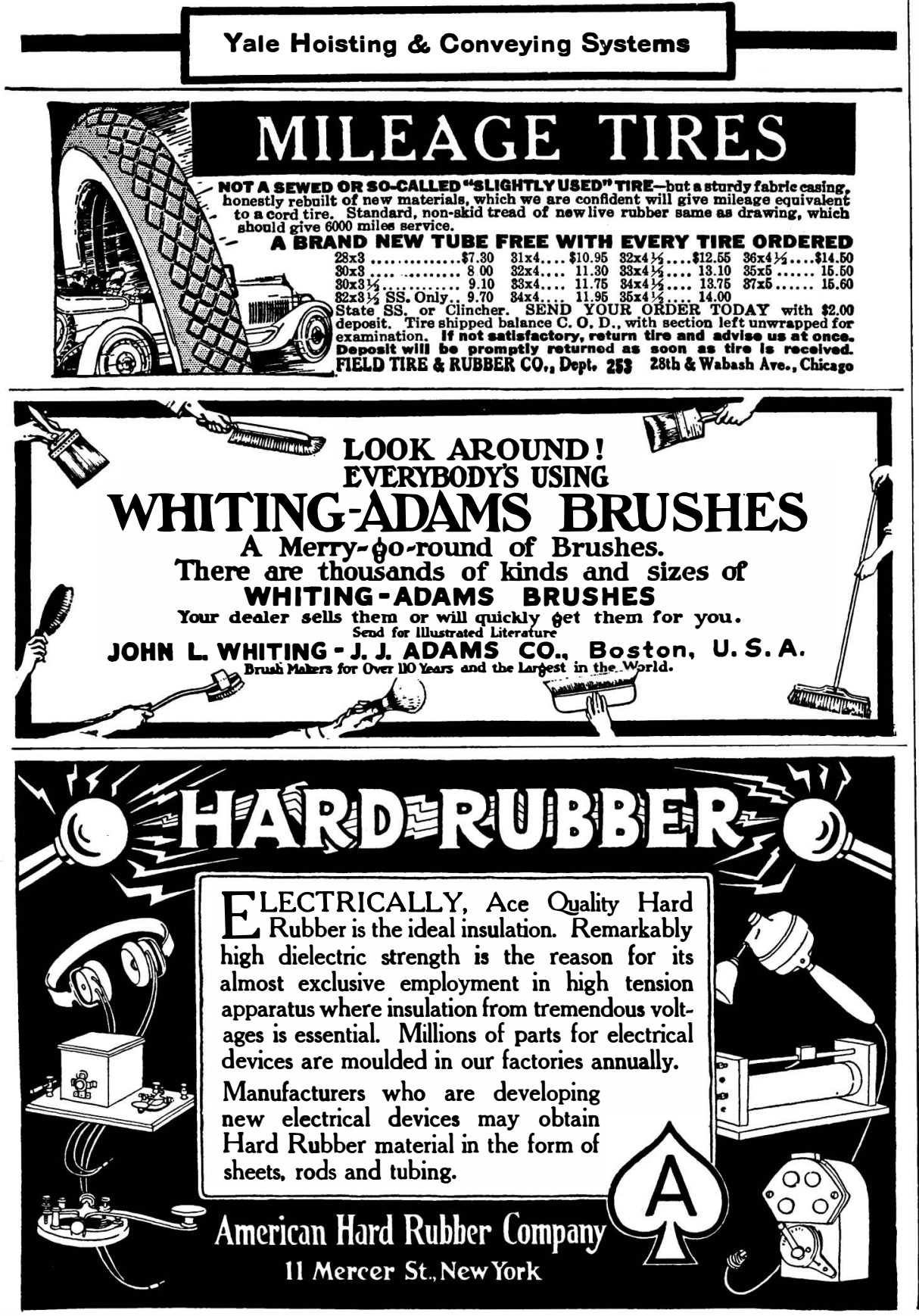

opment of a horsepower year, i.e., 8 tons,
this scheme would be tantamount to saving $16,000,000$ tons of that fuel annually. At $\$ 10$ a ton this would represent an economy of $\$ 160,000,000$ every twelvemonth. But quite apart from these considerations, there would be that inestimable gain in the matter of electrical energy that could be utilized for innumerable industrial purposes. Not only that, motive impulse at a moderate cost would be available for domestic services of many sorts.

We have led the world in the varied character and the magnitude of our electrochemical industries, and we can maintain our position in this respect only by continuing to provide great blocks of lowpriced current to meet the increasing demands for the commodities now manufactured at or near Niagara Falls. Final$l y$, let it be recalled that the two projects might prove exceedingly valuable sources of energy for that great superpower zone which is to embrace a far-flung section of the States of our northeastern seaboard. Isn't it worth our while to have at our disposal 3,500,000 horsepower without burning a single pound of coal? Can we be indifferent to undertakings that will enable us to increase vastly our productiveness while cutting the fuel bill by hundreds of millions of dollars yearly?

The Musical Hospital

Continued from page 270

Once in the hand of the violin doctor the broken pieces are tenderly taken out of the paper and an account of stock is taken to see what is missing. If the cracks are small they must be encouraged to open so a little glue can bẽ introduced and they are then tightly bound until dry. If the wound is more severe the cracks are taken up by inserting a narrow slip of wood with plents of stock left on the in side to shave off when dry. Small squares side to shave off when dry. Small squares
or "reinforcement blocks" will be noticed or "reinforcement blocks" will be noticed up and down the back and belly; these are crack and the square tops will be planed off before gluing together and varnishing. After all traces of the accident have been obliterated the instrument is carefully assembled and glued together, complicated clamps holding it in position during the drying operation, which is never hurried. Finally, the varnish is applied and the instrument is put away in a glass case out of the dust and in a few weeks and goes his way rejoicing.

The Heavens in April, 1921

(Continued from page 272)

Draco is high in the northeast, with Lyra below and Cygnus rising. High in the east is Bootes, with Corona and Hercules below and to the left, and Ophiuchus rising to the right. Virgo is well up in the south with Hydra below and extending far to the westward.

The winter constellations are almost gone. Orion and Taurus have set, and only Canis Minor, Gemini, and Auriga remain in sight. Leo, high in the southwest and brightened by the presence of conspicuous objects.

\section{The Planets}

Mercury is a morning star all this month, but is best observable at its be ginning, when he rises a little before 4 A. M. and should be easy to see. Venus begins as an evening star setting at 9 P. M. on the first, and appearing as a very strument as a powerful binocular; but she moves very rapidly into line between $u s$ and the sun, reaching her conjunction on the 22nd, so that during the last hal of the month she is practically invisible. Mars is an evening star in Aries, but is pretty low. On the 4th he is in conjunction with Venus; but as the two planets phenom degrees apart in decinatio

Jupiter is in Leo and is admirably obJupiter is in Leo and is admirably ob-
servable, coming to the meridian at about
P. M. in the middle of the month. Sais in the same constellation about ght degrees farther east, and is likewise onspicuous. With a powerful telescope is an exceedingly interesting object. n April 10th the rings are turned edgeise toward the sun, and after that date we shall be looking at their dark side ntil the end of July, and they will be quite invisible except in the most powerful telescopes, which will show them as a faint, ghostly line, illuminated partly by by sunlight transmitted through the interices of their particles.

Uranus is a morning star in Aquarius, rising about $3: 30 \mathrm{~A}$. M., while Neptune is in Cancer, and comes to the meridian at $: 30 \mathrm{P}$. M. in the middle of the month. The moon is new at $4 \mathrm{~A}$. M. on the 8 th, her first quarter at 5 A. M. on the 15 th, full at 2 A. M. on the $22 \mathrm{nd}$, and in her last quarter at $11 \mathrm{P}$. M. on the 29 th She is nearest us on the 16th, and farthest away on the 1st and 29th. During the month she passes near Uranus on the 5 th Mercury on the 6th, Venus and Mars on the 9 th, Neptune on the 16th, Jupiter on the 18th, and Saturn on the 19th

The month is notable for two eclipses, of the sun on the 8th and of the moon on the night of the 21st-22nd. The latter is visible throughout the United States and we shall describe it on the notes page next week. The solar eclipse on the 8th is annular, and visible in Europe-also, as a partial eclipse, in northern Africa, western Asia, and Greenland. Eclipse expeditions are not usual when the eclipse is only annular, but this time Dr. Fotheringham plans to go to see whether any stars are visible with the naked eye during the semi-darkness of the annular phase, hoping thus to obtain information of value in the interpretation of ancient and medieval eclipse records. At sea, S.S. "Aquitania,"

March 17, 1921.

\section{An Extinct Sea Lizard from}

Western Kansas

(Continued from page 279)

Doctor Williston, who observed on one pecimen carbonized pigment, which showed that the sides of the body were marked by narrow, diagonally placed parallel bars.

One of the unique features of Tylosaurus, and for that matter of all mosasaurs, is an articular joint in about the middle of each lower jaw, which permits considerable movement between the front and back parts, both up and down and sideways, though chiefly in the latter direc tion. This feature in conjunction with their very loose attachment to one another at the forward ends allowed the jaws to expand and thus enabled them to swallow large objects, for it is certain that not all of the animals which the Tylosaurus devoured were small, for since their teeth were not adapted for the rending of bodies they must have been swallowed whole.

While most of the Mosasaurs were predatory animals having the jaws provided with numerous sharply pointed teeth that were well adapted for catching fish-for their principal since fish bones and scales of Mosasaur, Globidens alabamensis, that formerly lived in North America and enjoyed quite a different kind of food as shown by the very peculiar shape of its teeth. Reference is made to a specimen in the National Museum found some few years ago in the northern part of the State of Alabama which has nearly spherical Alab.

Mosasaur specimens have not only been found in many parts of the United States, but in South America, Belgium, Holland, Russia, France and New Zealand, but nowhere are they more abundant or are their remains found in a more perfect state of preservation than in the chalk deposits of western Kansas. 


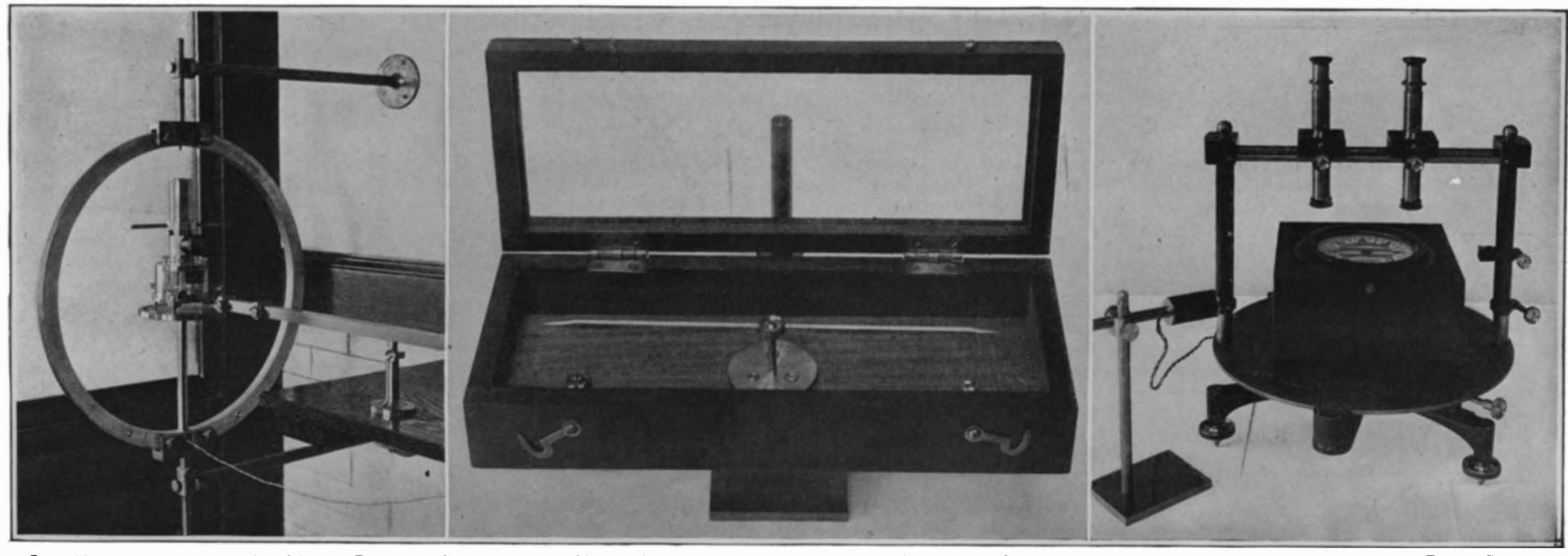

Left: New magnetometer designed by the Bureau of Standards for making a direct measurement of the magnetic moment of the needle system. Center: A standard compass. Right: Compass testing stand developed for determining the calibration error of compasses. Two telescopes are employed for sighting on the compass under test Some of the equipment used by the Bureau of Standards in testing magnetic compasses

Testing Magnetic Compasses

$A^{\text {LTHOUGH the subject of testing magnetic com- }}$ of Standards under the exigencies of war, complying with requests from the War Department and the United States Shipping Board, the investigations reveal information no less applicable in peace than in the days of human wreckage. The studies involving the conof human wreckage. The studies involving the con-
struction of special testing apparatus, observations as struction of special testing apparatus, observations as
to the behavior of varying types of instruments, and to the behavior of varying types of instruments, and the performances of indearth of scientific data relating to magnetic compasses previous to these experiments. Of outstanding interest, perhaps, in connection with the testing of compasses is the designing and installation by the Bureau of Standards of special equipmenta magnetometer for making a direct measurement of the magnetic moment of the needle system. R. L. Sanford, a physicist of the Bureau of Standards, technically describes the apparatus as a suspended system which carries besides the needle a concave mirror and an aluminum vane which swings in an enclosed cham. ber and serves to dampen the oscillations and bring ber and justable in position by means of which orientation and justable in position by means of which orientation and
sensitivity of the suspended needle can be controlled, is mounted on the instrument. When the control magnet is so stationed that the needle assumes an east-west position, it is possible to determine the magnetic moment to a degree of accuracy approximating five per cent without arresting the compass card. The latter is difficult of attainment in liquid-filled compasses. The magnetometer is mounted, with the suspended needle at the center of a large coil of known constants, thus facilitating calibration. A support is a fixture of the instrument for holding permanent bar magnets, used for compensating or adjusting compasses.

The presence of magnetic disturbances somewhat hampered the tests at the Bureau of Standards, a factor responsible for accuracy not in excess of five per cent. Pivot friction, calibration, period, and damping are the characteristics around which the testing of magnetic compasses revolves. Excessive pivot friction may result either from injury or imperfect materials, or from shabby workmanship. Sensitiveness to slight changes of direction is the object sought by the pivot friction test. The method of test consists of deflecting the compass by a small specified angle, and determining the difference in reading before and after the deflection. The test is repeated, the compass bowl being oriented in varying directions.

A simple testing stand, as illustrated by one of the photographs, was constructed for determining the calibration error of compasses. The table can be rotated about a vertical axis, graduated around its circumference so that ans angle which it may be turned can be read by means of an adjustable index. The use of a vernier insures the reading of angles to $0.1^{\circ}$. Two telescopes, stationed on uprights, are employed for sighting on the compass under test. A small coil is used for deflecting the compass while testing pivot friction, period, and damping. Compasses having vertical cards, when tested, necessitate a modification of the sighting arrangement. When testing for calibration, the compass is placed on this stand and the telescopes focused on the north and south points of the card. Forthwith the compass being tested is removed to a distance and the standard compass is given a berth on the stand. It is raised or lowered by negotiation of an adjustable stand till the index line is in focus. The telescopes are free from molestation after the initial adjustment. The table is oriented so that the image of the index line on the standard compass is in unison with the cross hairs of the telescopes. The adjustable index is set to zero and clamped. Once the table index has been adjusted by means of the standard compass the instrument to be tested is replaced on the stand and the error on the north heading determined by noting the difference between the compass reading and the index reading. The calibration error is the difference between the reading of the compass and the correct reading on any heading.

The so-called "period" or time of oscillation of a compass depends upon the moment of inertia of the card, the magnetic moments of the needles, and the horizontal intensity of the magnetic field. The test is made by a stop watch and auxiliary magnet or coil to start the compass swinging. The card is set swinging and the time observed for the half period or the com-

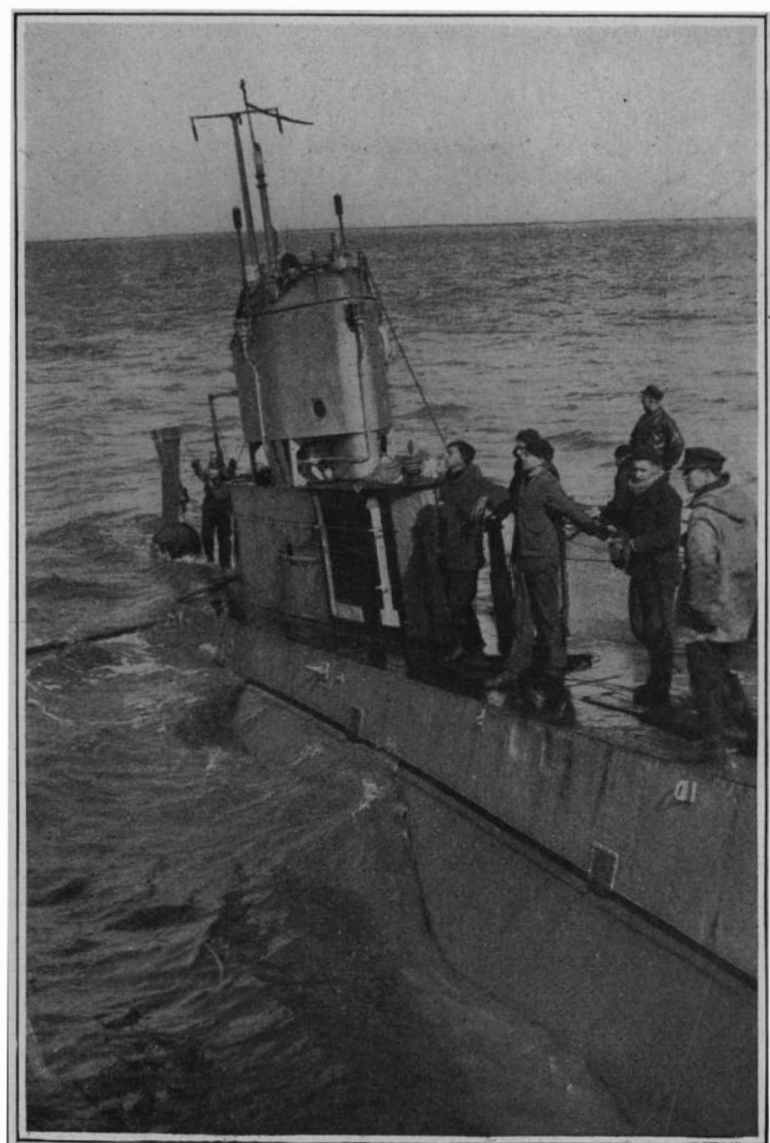

U. S. Submarine "L-1" partly submerged and being towed to a repair station plete period, as specifications may indicate. The period is taken as twice the time which elapses between successive transits of the card in opposite directions through its position of equilibrium when released from an initial deflection of $45^{\circ}$. The method of determining the damping of a marine compass is to find the ratio of two successive swings on the same side of the equilibrium.

\section{A New American Clay for Loading Paper}

HIGHLY colloidal clay which exists in large deA posits in the intermountain regions of the United states has been found by the United States Forest Products Laboratory to be valuable as a loading material for giving finish and printing qualities to book paper. When this clay is used in conjunction with English china clay, the retention of the English clay is materially increased, and the paper produced has a superior finish and appearance, and a more velvety feel. The admixture of this clay similarly improves the retention of other fillers, and is especially desirable with some which have a low retention.

The ability of the new clay to remain in suspension may make feasible the installation in paper mills of a central mixing plant, from which the loading material can be piped a considerable distance to the beaters, without danger of setting or clogging of the pipe lines, and with the assurance that the concentration will remain uniform. The properties and use of the new loading material are more fully described in a report which may be obtained from the laboratory on request.

\section{A Submarine in Trouble}

SBMARINES, like all other ships of the sea, have $\$$ their troubles; indeed, some people are inclined to think that they have more than their share. But we must remember that, in the very nature of things, the handling of a submarine is a far more difficult matter tlan the control and navigation of ships at the surface. Beautiful invention though the periscope is, the view which is obtained is not so complete as that of the captain on the bridge, and a search of the records will probably show that most injuries to submarines by collision have occurred when these little craft were submerged.

The accompanying photograph shows what happened to "L-1" when she was cruising off the Delaware capes, where she was rammed by the steam pilot boat "Philadelphia" and her hull was breached. Now, the perforation of her hull is a very serious matter for a submarine, if only for the reason that her reserve buoyancy is comparatively limited and any considerable inrush of water is sure to prove more than her pumps or other water-expelling means can take care of. In this particular case, the boat was saved by her commander running her on the beach in the innner harbor of the Delaware breakwater. The view which we present is taken looking aft, and the submergence of the after portion of the boat is due to the fact that her engine room is flooded with several feet of water. Fortunately, none of the crew was injured, and at the time that our photograph was taken members of the crew are on deck and the rescue boats are towing the submarine to a repair station. 